\title{
Radiative association and inverse predissociation of oxygen atoms
}

\section{Citation}

Babb, J. F., and A. Dalgarno. 1995. "Radiative Association and Inverse Predissociation of Oxygen Atoms." Physical Review A 51 (4): 3021-26. https://doi.org/10.1103/physreva.51.3021.

\section{Permanent link}

http://nrs.harvard.edu/urn-3:HUL.InstRepos:41417404

\section{Terms of Use}

This article was downloaded from Harvard University's DASH repository, and is made available under the terms and conditions applicable to Other Posted Material, as set forth at http:// nrs.harvard.edu/urn-3:HUL.InstRepos:dash.current.terms-of-use\#LAA

\section{Share Your Story}

The Harvard community has made this article openly available.

Please share how this access benefits you. Submit a story.

\section{Accessibility}




\title{
Radiative association and inverse predissociation of oxygen atoms
}

\author{
J. F. Babb and A. Dalgarno \\ Harvard-Smithsonian Center for Astrophysics, 60 Garden Street, Cambridge, MA 02138
}

(November 13, 2018)

\begin{abstract}
The formation of $\mathrm{O}_{2}$ by radiative association and by inverse predissociation of ground state oxygen atoms is studied using quantum-mechanical methods. Cross sections, emission spectra, and rate coefficients are presented and compared with prior experimental and theoretical results. At temperatures below $1000 \mathrm{~K}$ radiative association occurs by approach along the $1^{3} \Pi_{u}$ state of $\mathrm{O}_{2}$ and above $1000 \mathrm{~K}$ inverse predissociation through the $\mathrm{B}^{3} \Sigma_{u}^{-}$state is the dominant mechanism. This conclusion is supported by a quantitative comparison between the calculations and data obtained from hot oxygen plasma spectroscopy.
\end{abstract}

PACS number(s): 34.90.+q, 82.30.-b, 94.10.Fa, 95.30.Es 


\section{INTRODUCTION}

Of the 81 molecular electronic states that two $\mathrm{O}\left({ }^{3} \mathrm{P}\right)$ atoms can form, the repulsive $1{ }^{3} \Pi_{u}$ state can make an allowed electric dipole transition to the $\mathrm{X}^{3} \Sigma_{g}^{-}$ground state. Thus, the formation of an oxygen molecule through the direct radiative association reaction

$$
\mathrm{O}\left({ }^{3} \mathrm{P}\right)+\mathrm{O}\left({ }^{3} \mathrm{P}\right) \rightarrow \mathrm{O}_{2}\left(1^{3} \Pi_{u}\right) \rightarrow \mathrm{O}_{2}\left(\mathrm{X}^{3} \Sigma_{g}^{-}\right)+h \nu
$$

can occur and it might be an important molecular oxygen creation process at low temperatures. In Fig. 1 1 the potential energy curves for the $1^{3} \Pi_{u}$ and $\mathrm{X}^{3} \Sigma_{g}^{-}$states of $\mathrm{O}_{2}$ are depicted. Wraight [1] had suggested that the process (11) might be responsible for the emission in the near-infrared of the nightglow of the planet.

At higher temperatures another process-inverse predissociation, an indirect mechanism of association - can occur with the excited $\mathrm{B}^{3} \Sigma_{u}^{-}$state serving as an intermediate step in the formation of an oxygen molecule

$$
\mathrm{O}\left({ }^{3} \mathrm{P}\right)+\mathrm{O}\left({ }^{3} \mathrm{P}\right) \rightarrow \mathrm{O}_{2}^{*} \rightarrow \mathrm{O}_{2}\left(\mathrm{~B}^{3} \Sigma_{u}^{-}\right) \rightarrow \mathrm{O}_{2}\left(\mathrm{X}^{3} \Sigma_{g}^{-}\right)+h \nu
$$

where $\mathrm{O}_{2}^{*}$ denotes any one of the four states $1^{1} \Pi_{u}, 1^{3} \Pi_{u}, 1^{5} \Pi_{u}$, or $2^{3} \Sigma_{u}^{+}$that dissociate to $\mathrm{O}\left({ }^{3} \mathrm{P}\right)+\mathrm{O}\left({ }^{3} \mathrm{P}\right)$ and cross the $\mathrm{B}^{3} \Sigma_{u}^{-}$state. The predissociative coupling is due to spin-orbit (any of the four states) or electronic-rotational interaction $\left(1^{3} \Pi_{u}\right.$ state) [2]. Reaction (2) may be characterized by an activation energy that is the energy with respect to the $\mathrm{O}\left({ }^{3} \mathrm{P}\right)+\mathrm{O}\left({ }^{3} \mathrm{P}\right)$ asymptote at which the particular state $\mathrm{O}_{2}^{*}$ crosses the $\mathrm{B}^{3} \Sigma_{u}^{-}$state. The potential energy curve of the $\mathrm{B}^{3} \Sigma_{u}^{-}$state, which dissociates to an $\mathrm{O}\left({ }^{3} \mathrm{P}\right)$ atom and an $\mathrm{O}\left({ }^{1} \mathrm{D}\right)$ atom is shown in Fig. 1. Because the strength of the electronic-rotational coupling increases with the nuclear rotational angular momentum, while the strength of the spin-orbit coupling is nearly independent of it [3], the $1^{3} \Pi_{u}$ state is expected to be the most important channel for inverse predissociation. In a shock tube study of the emission from recombining oxygen atoms in a non-equilibrium shocked ozone-argon gas mixture at temperatures between 2500 and 3800 K Myers and Bartle [4] obtained absolute intensity measurements of the spectrum, 
and attributed the emission to the formation of oxygen molecules from ground state oxygen atoms through the inverse predissociation process

$$
\mathrm{O}\left({ }^{3} \mathrm{P}\right)+\mathrm{O}\left({ }^{3} \mathrm{P}\right) \rightarrow \mathrm{O}_{2}\left(1^{3} \Pi_{u}\right) \rightarrow \mathrm{O}_{2}\left(\mathrm{~B}^{3} \Sigma_{u}^{-}\right) \rightarrow \mathrm{O}_{2}\left(\mathrm{X}^{3} \Sigma_{g}^{-}\right)+h \nu
$$

The emission has been observed in several later experiments. It was seen in a silent electric discharge in $\mathrm{O}_{2}$ by Weisbeck and Völkner [5] and Sharma and Wray [6] measured emission intensities at 230 and $325 \mathrm{~nm}$ for temperatures in the range $2800-5300 \mathrm{~K}$ in shocked oxygen and oxygen-noble gas mixtures. Sharma and Wray [6] confirmed that the excited levels of $\mathrm{O}_{2}$ were populated by inverse predissociation but their emission spectra appear to be modified by vibrational redistribution. Similar conclusions were reached by Wray and Fried [7] who measured the emission intensities in an arc jet in oxygen and and oxygen-like gas mixtures. Hoffmann and Neiger [8,9] measured the absolute intensity of the emission from an equilibrium oxygen plasma at 8800, 9140, and $9420 \mathrm{~K}$, finding a peak at about $260 \mathrm{~nm}$ which they attributed to inverse predissociation (3). We return to a discussion of prior work in Sec. $\nabla$.

In this paper, we study quantum-mechanically the direct radiative association process (11) and the inverse predissociation process (3). Cross sections, emission spectra, and rate coefficients are determined for temperatures from 15 to $15000 \mathrm{~K}$. Improvements in the knowledge of the $1^{3} \Pi_{u}$ and $\mathrm{B}^{3} \Sigma_{u}^{-}$state potentials make it possible to get qualitative agreement with many experiments for the emission spectra and quantitative agreement for rate coefficients measured by Myers and Bartle [4].

\section{MOLECULAR STATES}

In Ref. [10 we constructed two $1^{3} \Pi_{u}$ potential energy curves that were identical except in the range of internuclear distances $2.4<R<3.1$ (we shall use atomic units in this section and Sec. [II). The first curve was designed to be consistent with the level shifts arising from predissociation of the $\mathrm{B}^{3} \Sigma_{u}^{-}$state, as analyzed in Ref. [1] where an internuclear distance for the $\mathrm{B}^{3} \Sigma_{u}^{-}-1{ }^{3} \Pi_{u}$ crossing $R_{x}=2.700$ was obtained, and which used ab initio energy 
calculations [12 for $3.1<R<10$. The second curve we constructed simply used the $a b$ initio calculations [12 for $2.5<R<10$. A recent analysis [13 of the photoabsorption cross section measurements [14], an analysis presumably more accurate than that of Ref. [11], yielded a different crossing point of $R_{x}=2.748$, which is consistent with the crossing point of the cubic spline fit [13] to the calculations of [12] at $R=2.5$ and 2.8. We have therefore used the second curve we constructed in Ref. [10 here. As we have discussed 10 the potential curve was supplemented for $R<2.4$ by the adjusted $a b$ initio energies of [15] and was constructed to have the proper asymptotic long-range behavior.

The adopted transition dipole moment function $D(R)$, defined in [16], for the transition from the $1^{3} \Pi_{u}$ to the $\mathrm{X}^{3} \Sigma_{g}^{-}$state was the semi-empirical determination of 17 for $1.5118 \leq$ $R \leq 2.5$ and the $a b$ initio calculation of 15 for $2.6 \leq R \leq 5$. The data were smoothly connected using cubic splines. For $R \leq 1.5118$ the function $D(R)=0.1794-0.01945 R$ was used and for $R \geq 5$ the function $D(R)=1.2625 / R^{3}$. The $\mathrm{X}^{3} \Sigma_{g}^{-}$state potential energy curve was constructed using RKR data for $1.79480<R<4.0840$ and fitted to the long-range form $-17.57 / R^{6}$ for $R>5$ as described in Ref. [18], but with a short-range form

$$
V(R)=5757.0053 \exp (-5.7925 R)
$$

The adopted $\mathrm{X}^{3} \Sigma_{g}^{-}$and $1^{3} \Pi_{u}$ potential curves, which correlate with the separated atoms $\mathrm{O}\left({ }^{3} \mathrm{P}\right)+\mathrm{O}\left({ }^{3} \mathrm{P}\right)$, are shown in Fig. 1. The $\mathrm{B}^{3} \Sigma_{u}^{-}$potential curve of [18] and the semi-empirical $\mathrm{B}^{3} \Sigma_{u}^{-}-\mathrm{X}^{3} \Sigma_{g}^{-}$transition dipole moment of [19] as described in [18] were utilized. In Fig. 11 the adopted $\mathrm{B}^{3} \Sigma_{u}^{-}$potential is shown. It correlates to the separated atom limit $\mathrm{O}\left({ }^{3} \mathrm{P}\right)+\mathrm{O}\left({ }^{1} \mathrm{D}\right.$, which lies 0.07229 au $(1.967 \mathrm{eV})$ above $\mathrm{O}\left({ }^{3} \mathrm{P}\right)+\mathrm{O}\left({ }^{3} \mathrm{P}\right)$.

\section{DIRECT RADIATIVE ASSOCIATION}

A fully quantum-mechanical theory can be formulated and used to calculate the cross sections at various energies and rate coefficients at various temperatures for direct radiative

association (11). Let $E$ be the energy of relative motion of the atoms approaching in the 
$1^{3} \Pi_{u}$ electronic state. The cross section for a transition to a bound vibration-rotation level $E_{v^{\prime \prime} N^{\prime \prime}}$ of the $\mathrm{X}^{3} \Sigma_{g}^{-}$molecular ground state is given in atomic units by [20,21]

$$
\sigma_{v^{\prime \prime} N^{\prime \prime N} N}(E)=\frac{g_{1}}{g} \frac{4 \pi^{2} \alpha^{3}}{3 \mu E}\left(E+E_{v^{\prime \prime} N^{\prime \prime}}\right)^{3} S_{J^{\prime \prime}, J}\left|M_{N^{\prime \prime}, N}\right|^{2}
$$

where $\mu=14583.10$ is the reduced mass for ${ }^{16} \mathrm{O}_{2}, g_{1}=3$ is the statistical weight of the $1{ }^{3} \Pi_{u}$ state (the nuclear spin is zero so only one of each lambda-doubling level is populated) and $g=81$ is the statistical weight of the $\mathrm{O}\left({ }^{3} \mathrm{P}\right)-\mathrm{O}\left({ }^{3} \mathrm{P}\right)$ pair, $\alpha$ is the fine structure constant, $S_{J^{\prime \prime}, J}$ is the Hönl-London factor, and

$$
M_{N^{\prime \prime}, N}=\int_{0}^{\infty} d R \psi_{v^{\prime \prime} N^{\prime \prime}}(R) D(R) \chi_{N}(R),
$$

with $\psi_{v^{\prime \prime} N^{\prime \prime}}(R)$ the normalized bound state wave function and $\chi_{N}(R)$ the energy-normalized wave function for the partial wave with angular momentum $N$ of the continuum $1^{3} \Pi_{u}$ state. The wave functions $\psi_{v^{\prime \prime} N^{\prime \prime}}$ and $\chi_{N}$ were calculated by integrating the Schrödinger equation using the Numerov method and $\chi_{N}$ was matched to the asymptotic form

$$
\chi_{N}(R) \sim(2 \mu / \pi k)^{1 / 2} \sin \left(k R+\delta_{N}-\frac{1}{2} N \pi\right), \quad R \sim \infty,
$$

with $k=(2 \mu E)^{1 / 2}$ and $\delta_{N}$ the phase shift. Due to the presence of identical nuclei in the diatom and the absence of nuclear spin, the $\mathrm{X}^{3} \Sigma_{g}^{-}$state is allowed only odd values $N^{\prime \prime}$. Let $J=|\mathbf{N}+\mathbf{S}|$ be the magnitude of the total angular momentum for the $1^{3} \Pi_{u}$ state, with $\mathbf{S}$ the total spin angular momentum and $|\mathbf{S}|=1$. Assuming that Hund's case (b) coupling applies, we have for $N \gg 1, J \sim N$ (in an unrelated study, case (b) was found to be a satisfactory approximation to intermediate coupling [18]) and then, summing over the rotational branches [22] for the allowed fine structure transitions for a given value of $N$ we obtain the line strength values given in Table [, which possess the sum rule property [23,24]

$$
\sum_{N^{\prime \prime}} S_{N^{\prime \prime}, N}=(2 S+1)(2 N+1) .
$$

In carrying out the computations $N^{\prime \prime}$ was required to be odd, but $N$ could be odd or even.

The total cross section, summed over allowed transitions between partial waves $N$ and final states $v^{\prime \prime} N^{\prime \prime}$, 


$$
\sigma(E) \equiv \frac{1}{(2 S+1)} \sum_{v^{\prime \prime} N^{\prime \prime} N} \sigma_{v^{\prime \prime} N^{\prime \prime} N}(E)
$$

is presented in Fig. 目 at various energies. Some structure, due to shape resonances, is apparent in the cross section at low energies. The cross section drops off rapidly for $E \gtrsim 0.4$ due to the loss of Franck-Condon overlap at small $R$. In computing the total cross sections values of $N$ up to 15 were sufficient for $E \lesssim 2.0 \times 10^{-5}$, up to 30 for $E \lesssim 3.0 \times 10^{-5}$, up to

100 for $E \lesssim 0.015$, and for $E \gtrsim 0.015$ values of $N$ up to 188 were used. Since the $\mathrm{X}^{3} \Sigma_{g}^{-}$state has 45 vibrational levels each total cross section at a given $E$ was a sum of many partial cross sections. Nevertheless, the computations could be carried out readily.

The cross sections obtained at various values of $E$ were used to obtain the rate coefficient at various temperatures by averaging over a Maxwellian velocity distribution,

$$
\alpha_{\mathrm{D}}(T)=\frac{2}{k T}\left(\frac{2}{\pi \mu k T}\right)^{1 / 2} \int_{0}^{\infty} E \sigma(E) e^{-E / k T} d E .
$$

The values are given in column 2 of Table 【. The rate coefficient is approximated to within $5 \%$ for $T<400 \mathrm{~K}$ by the expression

$$
\alpha_{\mathrm{D}}(T) \approx 9 \times 10^{-27} T^{-0.23} \exp (T / 70), \quad T<400 \mathrm{~K} .
$$

Wraight [1] estimated semiclassically the rate coefficient for the direct process (1) and found

$$
\alpha_{\mathrm{W}}(T) \sim 6 \times 10^{-24} T^{1.58} \mathrm{~cm}^{3} \mathrm{~s}^{-1},
$$

for $200 \mathrm{~K}<T<2000 \mathrm{~K}$. He advised caution in applying (12) to high temperatures. Expression (12) was adopted for astrophysical purposes in the tabulation of Prasad and Huntress [25] and in the UMIST data base [26]. The present computations show that Eq. (12) drastically overestimates the radiative association rate coefficient at low temperatures.

\section{INVERSE PREDISSOCIATION}

For inverse predissociation, (3), the rate coefficient at temperature $T$ is given by the Breit-Wigner expression [27 29] 


$$
\alpha(T)=\frac{g_{\mathrm{B}}}{g}\left(\frac{2 \pi}{\mu k T}\right)^{3 / 2} \sum_{v^{\prime}} \sum_{N^{\prime}}\left(2 N^{\prime}+1\right) \frac{\Gamma_{\mathrm{r}}\left(v^{\prime}, N^{\prime}\right) \Gamma_{\mathrm{d}}\left(v^{\prime}, N^{\prime}\right)}{\Gamma_{\mathrm{r}}\left(v^{\prime}, N^{\prime}\right)+\Gamma_{\mathrm{d}}\left(v^{\prime}, N^{\prime}\right)} \exp \left(-E_{v^{\prime} N^{\prime}} / k T\right),
$$

where $g_{\mathrm{B}}=3$ is the statistical weight of the $\mathrm{B}^{3} \Sigma_{u}^{-}$state, $g=81$ is the statistical weight of the $\mathrm{O}\left({ }^{3} \mathrm{P}\right)-\mathrm{O}\left({ }^{3} \mathrm{P}\right)$ pair, $E_{v^{\prime} N^{\prime}}$ is the energy of the level $v^{\prime} N^{\prime}$ of the $\mathrm{B}^{3} \Sigma_{u}^{-}$state measured with respect to the $\mathrm{O}\left({ }^{3} \mathrm{P}\right)-\mathrm{O}\left({ }^{3} \mathrm{P}\right)$ asymptote, $\Gamma_{\mathrm{r}}\left(v^{\prime}, N^{\prime}\right)$ and $\Gamma_{\mathrm{d}}\left(v^{\prime}, N^{\prime}\right)$ are, respectively, the radiative and predissociative widths of level $v^{\prime} N^{\prime}$, with

$$
\Gamma_{\mathrm{r}}\left(v^{\prime}, N^{\prime}\right)=\hbar A\left(v^{\prime}, N^{\prime}\right) \equiv \hbar \sum_{v^{\prime \prime} N^{\prime \prime}} A\left(v^{\prime} N^{\prime} v^{\prime \prime} N^{\prime \prime}\right),
$$

and $A\left(v^{\prime} N^{\prime} v^{\prime \prime} N^{\prime \prime}\right)$ is the Einstein $A$-coefficient. The sum in Eq. (13) is taken over levels $v^{\prime} N^{\prime}$ with energy greater than the energy of the crossing point. Analysis [13] of the predissociation in the $\mathrm{B}^{3} \Sigma_{u}^{-}$state indicates that the $1^{3} \Pi_{u}$ state crosses at an energy of 0.0435 relative to the $\mathrm{O}\left({ }^{3} \mathrm{P}\right)-\mathrm{O}\left({ }^{3} \mathrm{P}\right)$ asymptote [1] or about $13000 \mathrm{~K}$. For the $\mathrm{B}^{3} \Sigma_{u}^{-}$state, typically $\Gamma_{\mathrm{d}}\left(v^{\prime}, N^{\prime}\right) \gg$ $\Gamma_{\mathrm{r}}\left(v^{\prime}, N^{\prime}\right)$ [30], so that

$$
\alpha(T) \approx \frac{3}{81}\left(\frac{2 \pi}{\mu k T}\right)^{3 / 2} \sum_{v^{\prime}} \sum_{N^{\prime}}\left(2 N^{\prime}+1\right) \Gamma_{\mathrm{r}}\left(v^{\prime}, N^{\prime}\right) \exp \left(-E_{v^{\prime} N^{\prime}} / k T\right) .
$$

In evaluating (15) we made the approximation

$$
A\left(v^{\prime} N^{\prime} v^{\prime \prime} N^{\prime \prime}\right) \approx A\left(v^{\prime} 0 v^{\prime \prime} 0\right)\left[\left(E_{v^{\prime} N^{\prime}}-E_{v^{\prime \prime} N^{\prime \prime}}\right) /\left(E_{v^{\prime} 0}-E_{v^{\prime \prime} 1}\right)\right]^{3},
$$

with $N^{\prime} \approx N^{\prime \prime}$ leading to the formula

$$
\begin{aligned}
\alpha(T) \approx & \frac{3}{81}\left(\frac{2 \pi}{\mu k T}\right)^{3 / 2} \sum_{v^{\prime}} \sum_{v^{\prime \prime}} \hbar A\left(v^{\prime} 0 v^{\prime \prime} 0\right) \\
& \times \sum_{N^{\prime}}\left(2 N^{\prime}+1\right)\left[\left(E_{v^{\prime \prime} N^{\prime}}-E_{v^{\prime \prime} N^{\prime}}\right) /\left(E_{v^{\prime} 0}-E_{v^{\prime \prime} 1}\right)\right]^{3} \exp \left(-E_{v^{\prime} N^{\prime}} / k T\right) .
\end{aligned}
$$

The intensity of emission from a transition from level $\left(v^{\prime}, N^{\prime}\right)$ into level $\left(v^{\prime \prime}, N^{\prime \prime}\right)$ is then given by the expression

$$
\begin{aligned}
I_{\nu} \approx & h \nu_{v^{\prime} N^{\prime} v^{\prime \prime} N^{\prime \prime}} \frac{3}{81}(2 \pi / \mu k T)^{3 / 2}\left(2 N^{\prime}+1\right) \\
& \times \exp \left(-E_{v^{\prime} N^{\prime}} / k T\right) \hbar A\left(v^{\prime} 0 v^{\prime \prime} 0\right)\left[\left(E_{v^{\prime \prime} N^{\prime}}-E_{v^{\prime \prime} N^{\prime}}\right) /\left(E_{v^{\prime} 0}-E_{v^{\prime \prime} 1}\right)\right]^{3} .
\end{aligned}
$$

With $E\left(v^{\prime} N^{\prime} v^{\prime \prime} N^{\prime \prime}\right) \equiv h \nu_{v^{\prime} N^{\prime} v^{\prime \prime} N^{\prime \prime}}$ and $E_{v^{\prime} N^{\prime}}$ both in $\mathrm{cm}^{-1}, T$ in $\mathrm{K}$, and $A\left(v^{\prime} 0 v^{\prime \prime} 0\right)$ in $\mathrm{s}^{-1}$, we can express $I_{\nu}$ in $\mathrm{W}-\mathrm{cm}^{3}$ as

$$
I_{\nu}=\frac{3}{81}\left(4.7 \times 10^{-45}\right) E\left(v^{\prime} N^{\prime} v^{\prime \prime} N^{\prime \prime}\right)\left(1 / T^{3 / 2}\right)\left(2 N^{\prime}+1\right) A\left(v^{\prime} 0 v^{\prime \prime} 0\right) \exp \left(-E_{v^{\prime} N^{\prime}} / 0.695 T\right) .
$$




\section{RESULTS AND COMPARISON WITH EXPERIMENT}

Using a program of Allison [31,19] and the potentials and transition dipole moments of Sec. II the radiative widths were determined. They are in good agreement with other computations 31,32]. In Table III we present the values of the emission transition probabilities $A\left(v^{\prime}, 0\right)$ of the $\mathrm{B}^{3} \Sigma_{u}^{-}$state vibrational levels. In Fig. 3 the calculated emission spectra arising in inverse predissociation at $3000 \mathrm{~K}$ are shown in $\mathrm{W}-\mathrm{cm}^{3} / \mathrm{nm}$ along with the measurements of Myers and Bartle [4] at $3030 \mathrm{~K}$; the experimental points and error bars were interpolated from absolute emission-intensity spectral distribution curves. Our calculations support the suggestion that the measurements are in error for wavelengths $\lambda \lesssim 300 \mathrm{~nm}$, a possibility noted by Myers and Bartle [4] and Sharma and Wray [6]. The measurements of Sharma and Wray [6] and Wray and Fried [7] appear to be affected by vibrational redistribution and their spectral data can be better interpreted in terms of an equilibrium model of the vibrational level populations of the $\mathrm{B}^{3} \Sigma_{u}^{-}$state 33 .

In the measurements of Hoffmann and Neiger near $9000 \mathrm{~K}$ a strong broad continuum feature was observed at around $260 \mathrm{~nm}$. Our calculated emission spectra from inverse predissociation are consistent with the experimental observations. Measurements at higher wavelength resolution should reveal structure arising from the Schumann-Runge bands populated by inverse predissociation. We find an absolute emission intensity of about $5 \times 10^{-39} \mathrm{~W}-\mathrm{cm}^{3} / \mathrm{nm}$ at $250 \mathrm{~nm}$ and $9400 \mathrm{~K}$. From the measured absorption coefficient

of $K=2 \times 10^{-5} \mathrm{~cm}^{-1}$ [8], using Wien's radiation law [9,34], the length $10 \mathrm{~cm}$ of the experimental arc column, and estimating the number density [9] of $\mathrm{O}$ atoms of about $10^{18} \mathrm{~cm}^{-3}$ from Fig. 5 of Ref. [9], we obtain an experimental value of $2.5 \times 10^{-39} \mathrm{~W}-\mathrm{cm}^{3} / \mathrm{nm}$ at $250 \mathrm{~nm}$ and $9400 \mathrm{~K}$. The agreement to within a factor of two is remarkably close.

A rate coefficient

$$
\alpha_{\operatorname{Exp}}(T)=7.3 \times 10^{-18} \exp [(-14540 \pm 1100) / T] \mathrm{cm}^{3} \mathrm{~s}^{-1}, \quad 280 \leq \lambda \leq 500 \mathrm{~nm}
$$

for the total radiative combination of oxygen 


$$
\mathrm{O}+\mathrm{O} \rightarrow \mathrm{O}_{2}+h \nu
$$

between $2500 \mathrm{~K}$ and $3800 \mathrm{~K}$ was deduced by Myers and Bartle «1. In Table [1] values of $\alpha_{\operatorname{Exp}}(T)$ are given for various temperatures. Our values for the rate coefficient for inverse predissociation $\alpha_{\mathrm{IP}}(T)$ are included in Table 1 . The rate coefficient is fitted to within $10 \%$ for $T \leq 5000 \mathrm{~K}$ by the expression

$$
\alpha_{\mathrm{IP}}(T) \sim 6.4 \times 10^{-18} \exp (-13455 / T) \mathrm{cm}^{3} \mathrm{~s}^{-1}, \quad T \leq 5000 \mathrm{~K},
$$

and to within $5 \%$ for $5000 \leq T \leq 15000 \mathrm{~K}$ by

$$
\alpha_{\mathrm{IP}}(T) \sim\left(-5.6 \times 10^{-19}+2.4 \times 10^{-22} \mathrm{~T}-9.6 \times 10^{-27} T^{2}\right) \mathrm{cm}^{3} \mathrm{~s}^{-1}, \quad 5000 \leq T \leq 15000 \mathrm{~K} .
$$

In Fig. 1 the calculated direct $\alpha_{\mathrm{D}}$ and inverse predissociation $\alpha_{\mathrm{IP}}$ rates are presented and compared with the $\alpha_{\text {Exp }}$. The agreement is very good, confirming that the formation of molecular oxygen from hot oxygen atoms at low densities proceeds by inverse predissociation through the $\mathrm{B}^{3} \Sigma_{u}^{-}$state following approach along the $1^{3} \Pi_{u}$ state.

\section{ACKNOWLEDGEMENTS}

We would like to thank our colleagues B. Zygelman, K. Yoshino, J.-H. Yee, Y. Sun, R. D. Sharma, R. S. Friedman, M. L. Du, and A. C. Allison for sharing details of calculations and for helpful discussions. J. Yeh, formerly of Harvard University, assisted in the computation

of the inverse predissociation rate coefficients and P. C. Stancil and Z. Fan, formerly of the Harvard-Smithsonian Center for Astrophysics, made improvements to the program used to calculate the direct radiative association cross sections. JFB would like to thank P. S. Julienne and R. E. Meyerott for helpful discussions. This work has been supported by the National Science Foundation, Division of Atmospheric Sciences under Grant No. 9320175 and by grants for the Institute for Theoretical Atomic and Molecular Physics to the Smithsonian Astrophysical Observatory and Harvard University. 


\section{REFERENCES}

[1] P. C. Wraight, Planet. Space Sci. 25, 787 (1977).

[2] P. S. Julienne and M. Krauss, J. Mol. Spectrosc. 56, 270 (1975).

[3] H. Lefebvre-Brion and R. W. Field, Perturbations in the spectra of diatomic molecules (Academic Press, Orlando, 1986).

[4] B. F. Myers and E. R. Bartle, J. Chem. Phys. 48, 3935 (1968).

[5] R. Weisbeck and A. Völkner, Z. angew. Physik 32, 258 (1971).

[6] R. D. Sharma and K. L. Wray, J. Chem. Phys. 54, 4578 (1971).

[7] K. L. Wray and S. S. Fried, JQSRT 11, 1171 (1971).

[8] H. Hoffmann and M. Neiger, Z. Naturforsch. 33A, 1099 (1978).

[9] H. Hoffmann, JQSRT 21, 163 (1979).

[10] J. F. Babb, Y. Sun, M. J. Jamieson, A. Dalgarno, and A. C. Allison, JQSRT 50, 579 (1993).

[11] S. S.-L. Chiu, A. S-C. Cheung, M. Finch, M. J. Jamieson, K. Yoshino, A. Dalgarno, and W. H. Parkinson, J. Chem. Phys. 97, 1787 (1992).

[12] H. Partridge, C. W. Bauschlicher, Jr., S. R. Langhoff, and P. R. Taylor, J. Chem. Phys. 95, 8292 (1991).

[13] B. R. Lewis, S. T. Gibson, and P. M. Dooley, J. Chem. Phys. 100, 7012 (1994).

[14] K. Yoshino, J. R. Esmond, A. S-C. Cheung, D. E. Freeman, and W. H. Parkinson, Planet. Spa. Sci. 40, 185 (1992).

[15] A. C. Allison, S. L. Guberman, and A. Dalgarno, J. Geophys. Res. 87, A923 (1982).

[16] S. L. Guberman and A. Dalgarno, J. Geophys. Res. 84, A4437 (1979). 
[17] J. Wang, D. G. McCoy, A. J. Blake, and L. Torop, JQSRT 38, 19 (1987).

[18] R. S. Friedman, JQSRT 43, 225 (1990).

[19] A. C. Allison, S. L. Guberman, and A. Dalgarno, J. Geophys. Res. 91, A10193 (1986).

[20] D. R. Bates, Mon. Not. R. Astron. Soc. 111, 303 (1951).

[21] H. B. Palmer, J. Chem. Phys. 47, 2116 (1967).

[22] P. Nolan and F. A. Jenkins, Phys. Rev. A 50, 943 (1936).

[23] A. Schadee, JQSRT 19, 451 (1978).

[24] E. E. Whiting, A. Schadee, J. B. Tatum, J. T. Hougen, and R. W. Nicholls, J. Molec. Spectrosc. 80, 249 (1980).

[25] S. S. Prasad and W. T. Huntress, Jr., Ap. J. Suppl. 43, 1 (1980), reaction 1184.

[26] T. J. Millar, J. M. C. Rawlings, A. Bennett, P. D. Brown, and S. B. Charnley, Astron. and Astrophys. Suppl. 87, 585 (1991), reaction 259.

[27] R. A. Bain and J. N. Bardsley, J. Phys. B 5, 277 (1972).

[28] M. F. Golde and B. A. Thrush, Rep. Prog. Phys. 36, 1285 (1973).

[29] M. L. Du and A. Dalgarno, J. Geophys. Res. 95, A12265 (1990).

[30] P. C. Cosby, H. Park, R. A. Copeland, and T. G. Slanger, J. Chem. Phys. 98, 5117 (1993).

[31] A. C. Allison, A. Dalgarno, and N. W. Pasachoff, Planet. Space Sci. 19, 1463 (1971).

[32] C. O. Laux and C. H. Kruger, JQSRT 48, 9 (1992).

[33] R. A. Allen, NASA Contractor Report CR-557, Avco Corporation (unpublished).

[34] S. S. Penner, Quantitative molecular spectroscopy and gas emissivities (Addison-Wesley, Reading, Massachusetts, 1959), p. 9. 


\section{TABLES}

TABLE I. Line strengths for transitions from the $1^{3} \Pi_{u}$ to the $\mathrm{X}^{3} \Sigma_{g}^{-}$state.

\begin{tabular}{ccc}
\hline \hline$J^{\prime \prime}$ & Branch & $S_{J^{\prime \prime}, J} /(2 S+1)$ \\
\hline$J-1$ & $R$ & $J+1$ \\
$J$ & $Q$ & $2 J+1$ \\
$J+1$ & $P$ & $J$ \\
\hline \hline
\end{tabular}


TABLE II. Rate coefficients in $\mathrm{cm}^{3} \mathrm{~s}^{-1}$, as a function of temperature $T$, in $K$, for direct radiative association process (11), inverse predissociation (3), and the experimentally derived value for the total process (21). Numbers in square brackets represent powers of 10 .

\begin{tabular}{|c|c|c|c|}
\hline & & Inverse & Experiment, Ref. 迎 \\
\hline$T(K)$ & Direct & Predissociation & $\alpha_{\text {Exp }}$, Eq. (20) \\
\hline 15 & $6.0[-27]$ & & \\
\hline 30 & $6.4[-27]$ & & \\
\hline 50 & $7.4[-27]$ & & \\
\hline 100 & $1.3[-26]$ & & \\
\hline 200 & $4.6[-26]$ & & \\
\hline 300 & $1.7[-25]$ & & \\
\hline 400 & $6.5[-25]$ & & \\
\hline 500 & $1.9[-24]$ & & \\
\hline 600 & $4.4[-24]$ & $1.1[-27]$ & \\
\hline 700 & $8.3[-24]$ & $2.7[-26]$ & \\
\hline 800 & $1.4[-23]$ & $3.1[-25]$ & \\
\hline 900 & $2.1[-23]$ & $2.0[-24]$ & \\
\hline 1000 & $2.9[-23]$ & $9.2[-24]$ & \\
\hline 1200 & $4.7[-23]$ & $8.9[-23]$ & \\
\hline 1400 & $6.9[-23]$ & $4.5[-22]$ & \\
\hline 1600 & $9.2[-23]$ & $1.5[-21]$ & \\
\hline 1800 & $1.2[-22]$ & $3.9[-21]$ & \\
\hline 2000 & $1.4[-22]$ & $8.4[-21]$ & $5.1[-21]$ \\
\hline 2200 & $1.6[-22]$ & $1.5[-20]$ & $9.8[-21]$ \\
\hline 2500 & $2.0[-22]$ & $3.2[-20]$ & $2.2[-20]$ \\
\hline 2700 & $2.2[-22]$ & $4.8[-20]$ & $3.3[-20]$ \\
\hline 3000 & $2.5[-22]$ & $7.8[-20]$ & $5.7[-20]$ \\
\hline
\end{tabular}




\begin{tabular}{llcc}
4000 & $3.7[-22]$ & $2.2[-19]$ & $1.9[-19]$ \\
5000 & $6.1[-22]$ & $3.9[-19]$ & $4.0[-19]$ \\
10000 & $1.7[-20]$ & $9.0[-19]$ & \\
15000 & $7.3[-20]$ & $9.3[-19]$ & \\
\hline \hline
\end{tabular}


TABLE III. Transition probabilities $A\left(v^{\prime}, 0\right)$ for emission from the $\mathrm{B}^{3} \Sigma_{u}^{-}$to $\mathrm{X}^{3} \Sigma_{g}^{-}$states in units of $10^{7} \mathrm{~s}^{-1}$ for various values of the $\mathrm{B}^{3} \Sigma_{u}^{-}$vibrational quantum number $v^{\prime}$ with $N^{\prime}=0$.

\begin{tabular}{llcr}
\hline \hline$v^{\prime}$ & $A\left(v^{\prime}, 0\right)$ & $v^{\prime}$ & $A\left(v^{\prime}, 0\right)$ \\
\hline 0 & 1.816 & 11 & 1.750 \\
1 & 1.916 & 12 & 1.586 \\
2 & 2.006 & 13 & 1.393 \\
3 & 2.078 & 14 & 1.184 \\
4 & 2.130 & 15 & 0.9709 \\
5 & 2.157 & 16 & 0.7833 \\
6 & 2.157 & 17 & 0.6162 \\
7 & 2.129 & 18 & 0.4710 \\
8 & 2.073 & 19 & 0.3414 \\
9 & 1.992 & 20 & 0.2254 \\
10 & 1.883 & 21 & 0.1195 \\
\hline \hline
\end{tabular}




\section{FIGURES}

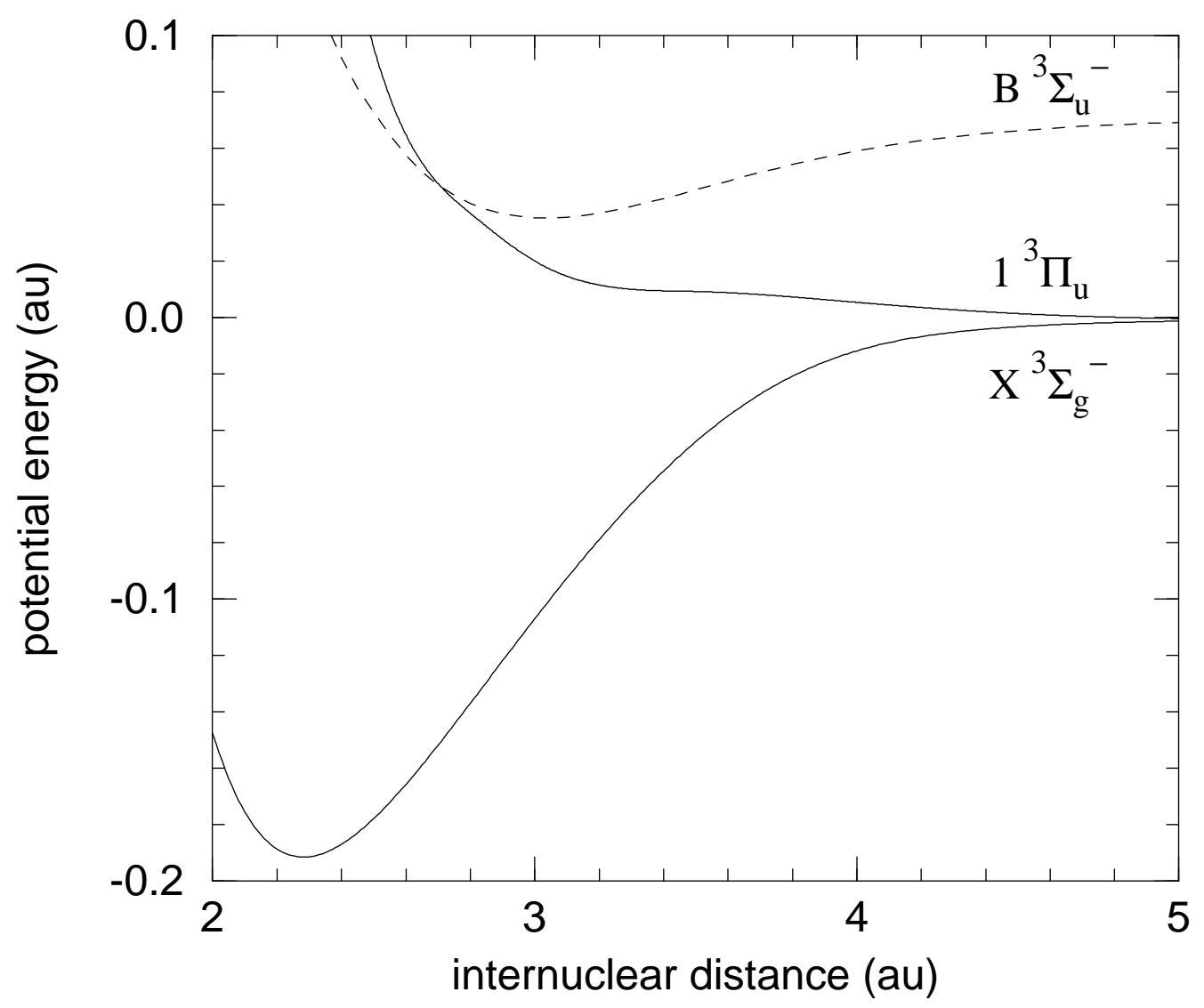

FIG. 1. Adopted $1^{3} \Pi_{u}, \mathrm{~B}^{3} \Sigma_{u}^{-}$, and $\mathrm{X}^{3} \Sigma_{g}^{-}$potentials. 


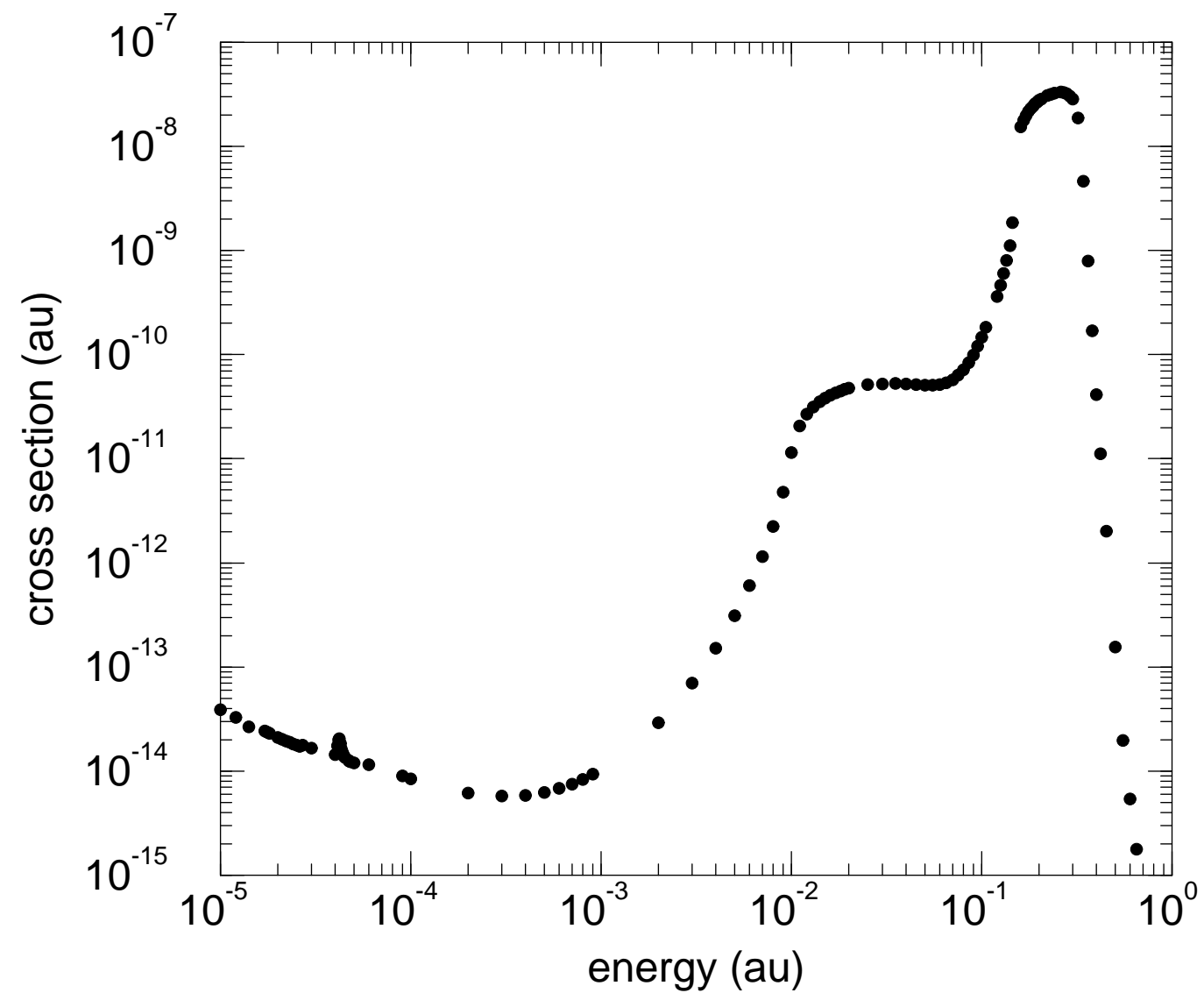

FIG. 2. Cross section $\sigma(E)(9)$ in au $\left(a_{0}^{2}\right)$ for the direct radiative association process (1) as a function of energy $E$ in au $\left(e^{2} / a_{0}\right)$. 


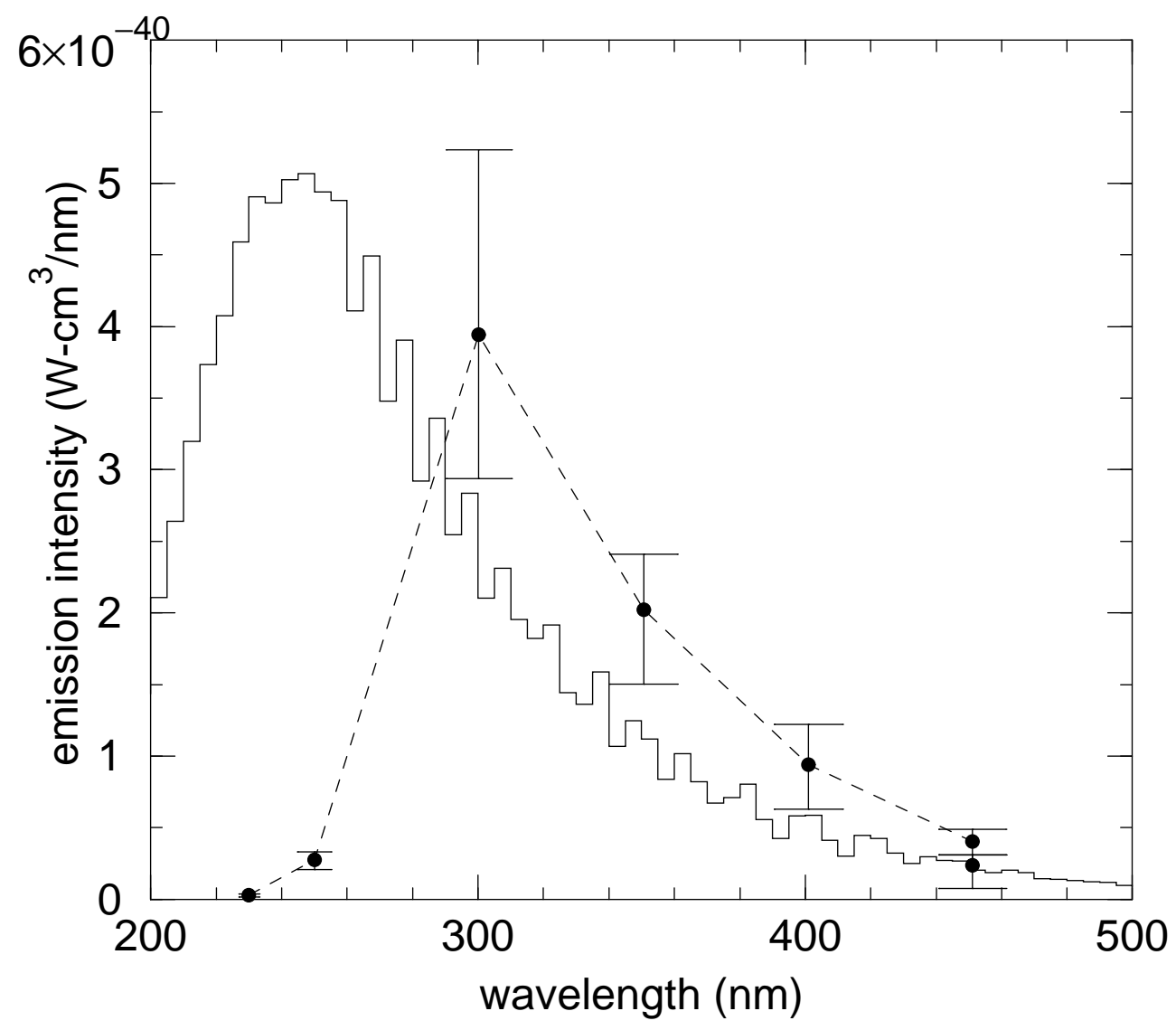

FIG. 3. Absolute emission intensity at various wavelengths calculated for inverse predissociation at $3000 \mathrm{~K}$ (solid line), compared to experimental measurements of Myers and Bartle at $3030 \mathrm{~K}$ (points with error bars connected by the dotted line). The calculated spectrum has been averaged over bins of width $5 \mathrm{~nm}$. The experimental data are average values over a spectral interval the width of which is represented by the horizontal span of the error bar. 


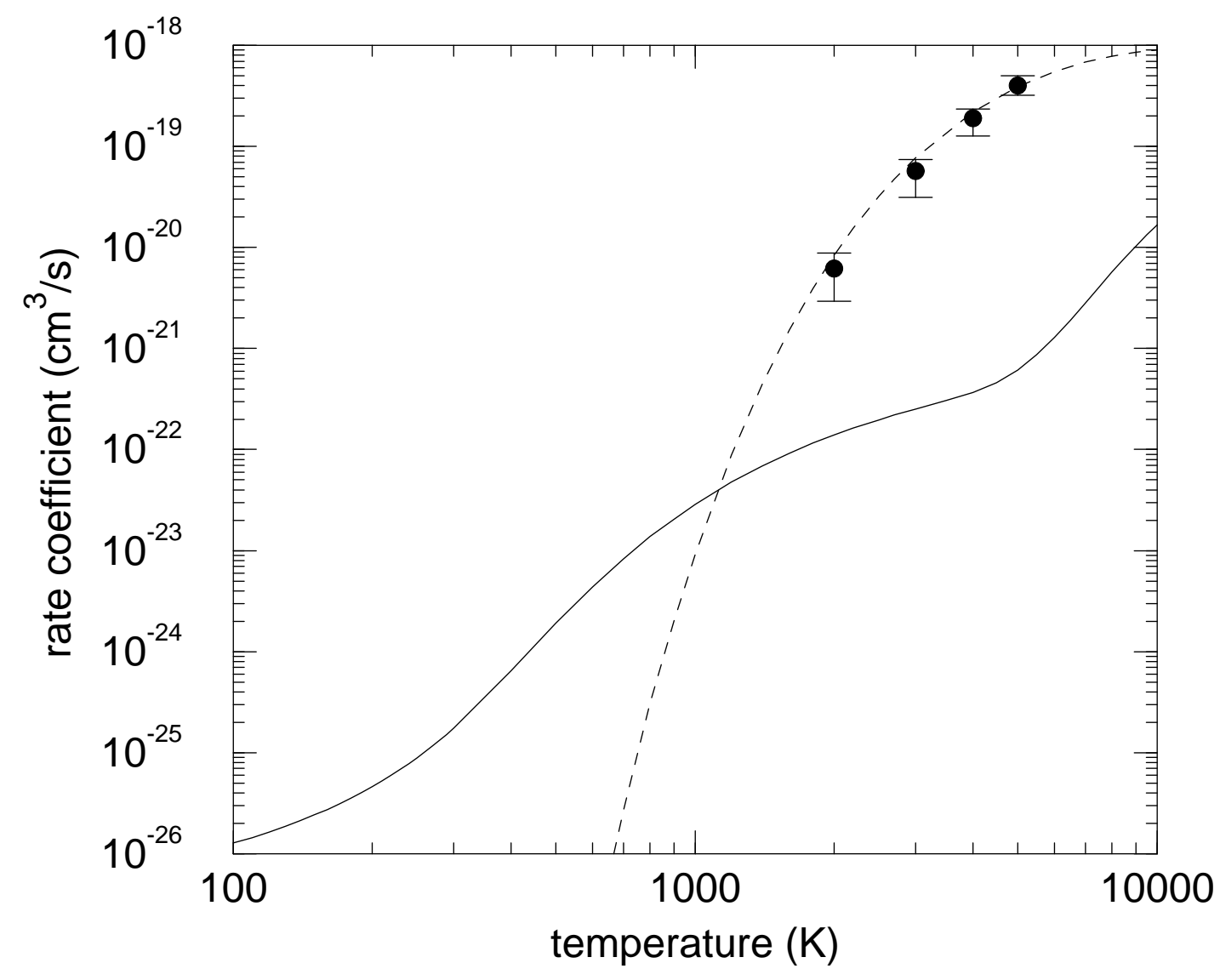

FIG. 4. Comparison of the calculated direct radiative association (solid line) and inverse predissociation (dotted line) rate coefficients and the experimental rate coefficient (points with error bars) of Myers and Bartle. 